\title{
A Utilização de tabaco entre adolescentes de uma escola na zona oeste do Rio de Janeiro.
}

\author{
Maria Regina Bernardo Silva \\ Universidade Estácio de Sá \\ Bruno Ferreira do Serrado Barbosa \\ Universidade do Estado do Rio de Janeiro \\ Tatiane Silva Chaves \\ Universidade Castelo Branco \\ Gabriella de Carvalho Miranda \\ Universidade Castelo Branco \\ Andressa Pereira Costa \\ Universidade Castelo Branco \\ E-mail: andressa.pereiracosta@yahoo.com.br
}

\section{Como citar:}

SILVA, Maria Regina Bernardo et al. A Utilização de tabaco entre adolescentes de uma escola na zona oeste do Rio de Janeiro. In: II SIMPÓSIO NACIONAL SOBRE ADOLESCÊNCIA: VULNERABILIDADE, PROTAGONISMOS

E DESAFIOS, 2. 2016, São Paulo. Anais...[S.I]: 2016. p. 20-21.

DOI: http://dx.doi.org/10.22388/2525-5894.2016.001

Introdução: o presente estudo apresenta relato de professores e acadêmicos de enfermagem, com alunos adolescentes de uma escola privada na zona oeste do Rio de Janeiro a qual a abordagem dos demais envolvidos foi sobre o conhecimento e uso de tabaco. O consumo de drogas entre os adolescentes se inicia entre 9 a 14 anos, sendo que destes 11\% usam tabaco e 51.2\% bebidas alcoólicas. Esta situação se agrava em função de baixo nível sócio-cultural.

Objetivos: relatar a experiência de atividades educativas realizada com adolescentes de uma Escola privada na zona oeste da cidade do Rio de Janeiro.

Metodologia: foi utilizada a técnica de observação participante em três encontros, com perguntas escritas e inclusive alguns se sentiram à vontade para perguntar espontaneamente sobre o assunto em questão, à atividade foi realizada com 38 adolescentes de 14 a 17 anos de idade, de ambos os sexos, de uma turma do curso técnico em enfermagem, de uma escola privada no bairro de Realengo na cidade do Rio de Janeiro após autorização do comitê da UCB 14/2012.

Resultados: relatos destacam que $54 \%$ destes adolescentes são fumantes desde 12 a 13 anos de idade. $22 \%$ dos adolescentes relataram que a motivação do fumo aconteceu em casa com os familiares e $32 \%$ através de amigos. Sendo que $32 \%$ informaram também utilizar álcool sempre que iam a festas. No Brasil e em outros países podemos observar a ocorrência em faixa etária cada vez mais precoce o início do vício de fumar e o aumento da prevalência de tabagismo em adolescentes. 
Conclusão: observou-se a importância da continuidade desta relação de confiança com os adolescentes, pois o assunto abordado ainda é cheio de estigmas e incertezas. Essa atividade educativa possibilitou, mediante a credibilidade na equipe de saúde que os adolescentes relatassem o que favoreceu a iniciação ao tabagismo e também a equipe fez abordagens em relação a iniciação e ao favorecimento de amigos em relação ao consumo do tabaco e seus malefícios. Mas é preocupante o fato relatado, "quando quiser paro de fumar" sabe-se que o tabagismo provoca dependência física e psíquica e que é difícil deixar de fumar. Mas algo foi observado como positivo uma vez que os adolescentes demonstraram credibilidade nas ações, vinculação com a equipe e boa interação com as atividades desenvolvidas.

Palavras-chave: Adolescentes. Tabagismo. Escola. Familiares. Enfermagem.

\section{Referências}

1- BRASIL. Ministério da Saúde. Secretaria Executiva. Secretaria de Atenção a Saúde. Coordenação Nacional DST/AIDS. A política do Ministério da Saúde para a Atenção Integral aos Usuários de Álcool e Outras Drogas. Brasília: BRASIL/MS, 2003. Acesso em: 31 de maio de 2012. Disponível em http://bvsms.saude.gov.br/bvs/publicacoes/pns alcool drogas.pdf 2- _. Ministério da Saúde. Instituto Nacional do Câncer. Por um mundo sem tabaco: mobilização da sociedade civil. Ação global para o controle do tabaco o 10 Tratado Internacional de Saúde Pública. 3a ed. Rio de Janeiro: INCA; 2004. Acessado em: 31 de maio de 2012. Disponível em:

http://www.inca.gov.br/tabagismo/cquadro3/acao global.pdf 